\title{
Ventilatory function in the Eisenmenger syndrome
}

\author{
C G C MacARThUR, D HUNTER, AND G J GIBSON ${ }^{1}$
}

From the Department of Medicine (Clinical Cardiology and Respiratory Medicine), Royal Postgraduate Medical School, Hammersmith Hospital, London, UK

ABSTRACT Ventilatory function and carbon monoxide transfer factor were studied in nine adult patients with post-tricuspid intracardiac defects and the Eisenmenger syndrome. A consistent mild defect of ventilatory function was found, with raised residual volume and closing capacity and reduction of other lung volumes and maximal expiratory flows. Maximal expiratory flow was particularly reduced at low lung volumes. One of the four subjects in whom pressure-volume studies were performed showed loss of normal elastic recoil at low lung volumes. A significant poorly ventilated space was excluded since the volume of distribution of helium during a 10 second breath-hold at full inspiration was close to plethysmographically measured total lung capacity. Carbon monoxide transfer factor, after correction for haemoglobin concentration, was $77 \%$ of predicted normal values. Sequential assessment of carbon monoxide transfer factor might be useful in the early diagnosis of pulmonary vascular disease in infants with large intracardiac defects, since it is likely to be raised early due to high pulmonary blood flow and will fall with the development of pulmonary vascular disease.

There have been few reports of the effects of hypertensive pulmonary vascular disease on ventilatory function. Furthermore, most reports have reflected a mixed population with both preand post-tricuspid shunts (McIlroy and Apthorp, 1958; Auchincloss et al, 1959; Woolf, 1963; McCredie et al, 1964; Kimball and Mcllroy, 1966). In general, respiratory function has appeared to be little affected by pulmonary vascular disease, and no consistent defect has been defined.

McKenzie et al (1977) have shown that the ventilatory washout of an injected bolus of radioactive nitrogen-13 was delayed compared with the clearance of an inhaled bolus in children with hypertensive pulmonary vascular disease. They proposed that the delayed clearance of the injected bolus was caused by the presence of poorly ventilated but perfused alveoli, possibly in association with an increased closing capacity.

The purpose of this study was to measure ventilatory function and gas transfer in a welldefined group of adult patients with post-tricuspid shunts and the Eisenmenger syndrome, to investigate the proposed mechanism for the results of the nitrogen-13 test, and to assess whether any consistent ventilatory defects occur in hypertensive

'Present address: Regional Cardiothoracic Centre, Freeman Hospital, Freeman Road, Newcastle-upon-Tyne NE7 7DN. pulmonary vascular disease, which might aid early diagnosis of this condition.

\section{Subjects and methods}

Cardiac catheterisation had proved that all subjects had post-tricuspid intracardiac defects, equal pulmonary and systemic pressures, and severely increased pulmonary vascular resistance (table 1). There were five men and four women aged between 20 and 46 years (mean 27). Two of the men $\frac{3}{3}$ were smokers (table 2). None of the subjects had any respiratory symptoms other than dyspnoea on exertion.

Forced expiratory volume in one second $\left(\mathrm{FEV}_{1}\right)$ and vital capacity (VC) were measured with a dry o spirometer (McDermott et al, 1968) and total lung N capacity (TLC) by plethysmography (Dubois et al, N 1956). Maximum values for $\mathrm{FEV}_{1}$ and VC were taken, but for TLC the mean of the two to four highest values agreeing to within $5 \%$ was taken. Residual volume (RV) was computed by subtracting VC from TLC.

Single breath carbon monoxide transfer factor $\frac{T}{0}$ (TLCO) was measured by the method of Ogilvie $\overrightarrow{\mathbb{D}}$

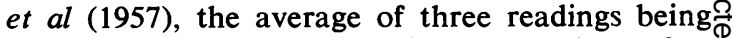
taken. This was repeated in one subject aftero haemoglobin reduction by repeated venesections? 
Table 1 Results of cardiac catheterisation

\begin{tabular}{|c|c|c|c|c|c|c|c|}
\hline Case No & $\begin{array}{l}\text { Age } \\
(y r)\end{array}$ & Diagnosis & $\begin{array}{l}P A P \\
(m m H g)\end{array}$ & $\begin{array}{l}S A P \\
(m m H g)\end{array}$ & $\begin{array}{l}Q p \\
\left(L / M i n / M^{2}\right)\end{array}$ & $\begin{array}{l}Q s \\
\left(L / M i n / M^{2}\right)\end{array}$ & $\begin{array}{l}\text { PAR } \\
\left(\text { Units } \times M^{2}\right)\end{array}$ \\
\hline $\begin{array}{l}1 \\
2 \\
3 \\
4 \\
4 \\
5 \\
6 \\
7 \\
8 \\
9\end{array}$ & $\begin{array}{r}9 \\
32 \\
21 \\
24 \\
11 \\
17 \\
22 \\
27 \\
17\end{array}$ & $\begin{array}{l}\text { VSD,ASD } \\
\text { VSD } \\
\text { PDA } \\
\text { VSD,PDA } \\
\text { DORV } \\
\text { SV } \\
\text { SV } \\
\text { PDA } \\
\text { VSD }\end{array}$ & $\begin{array}{l}125 / 85 \\
120 / 65 \\
120 / 60 \\
100 / 60 \\
100 / 60 \\
115 / 50 \\
110 / 70 \\
120 / 70 \\
145 / 80\end{array}$ & $\begin{array}{l}130 / 90 \\
120 / 75 \\
120 / 80 \\
100 / 60 \\
105 / 65 \\
115 / 75 \\
110 / 75 \\
125 / 80 \\
140 / 95\end{array}$ & $\begin{array}{l}5 \cdot 6 \\
1.4 \\
2.8 \\
1.9 \\
2.5 \\
4 \cdot 2 \\
2.5 \\
2.0 \\
1.9\end{array}$ & $\begin{array}{l}5 \cdot 8 \\
3 \cdot 1 \\
4 \cdot 0 \\
4 \cdot 7 \\
3 \cdot 7 \\
1 \cdot 9 \\
3 \cdot 2 \\
1 \cdot 7 \\
3 \cdot 0\end{array}$ & $\begin{array}{l}17 \\
48 \\
29 \\
42 \\
31 \\
18 \\
34 \\
38 \\
50\end{array}$ \\
\hline
\end{tabular}

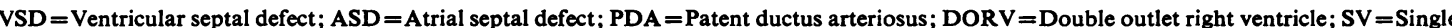
ventricle; $\mathrm{PAP}=\mathrm{Pulmonary}$ artery pressure $\mathbf{S A P}=$ Systemic arterial pressure; $\mathrm{Qp}=$ Pulmonary blood flow; $\mathrm{Qs}=\mathrm{Systemic}$ blood flow; and $\mathrm{PAR}=$ Pulmonary arteriolar resistance.

Table 2 Clinical data and results of spirometry and plethysmography

\begin{tabular}{|c|c|c|c|c|c|c|c|c|c|c|}
\hline $\begin{array}{l}\text { Case } \\
\text { No }\end{array}$ & Sex & $\begin{array}{l}\text { Age } \\
(y r)\end{array}$ & Smoker & $\begin{array}{l}\text { PEFR } \\
\text { Per cent of } \\
\text { predicted } \\
\text { normal values }\end{array}$ & $F E V_{1}$ & $V C$ & $F E V_{1} / V C$ & $R V$ & $T L C$ & $R V / T L C$ \\
\hline $\begin{array}{l}1 \\
2 \\
3 \\
4 \\
5 \\
6 \\
7 \\
8 \\
9\end{array}$ & $\begin{array}{l}\mathbf{M} \\
\mathbf{M} \\
\mathbf{M} \\
\mathbf{M} \\
\mathbf{M} \\
\mathbf{F} \\
\mathbf{F} \\
\mathbf{F} \\
\mathbf{F}\end{array}$ & $\begin{array}{l}20 \\
46 \\
29 \\
24 \\
22 \\
24 \\
26 \\
33 \\
20\end{array}$ & $\begin{array}{l}\text { NO } \\
\text { NO } \\
\text { YES } \\
\text { YES } \\
\text { NO } \\
\text { NO } \\
\text { NO } \\
\text { NO } \\
\text { NO }\end{array}$ & $\begin{array}{r}68 \\
115 \\
71 \\
69 \\
79 \\
88 \\
89 \\
82 \\
84\end{array}$ & $\begin{array}{l}63 \\
79 \\
87 \\
76 \\
93 \\
91 \\
78 \\
79 \\
72\end{array}$ & $\begin{array}{r}64 \\
88 \\
95 \\
92 \\
100 \\
98 \\
74 \\
77 \\
83\end{array}$ & $\begin{array}{r}96 \\
91 \\
90 \\
81 \\
94 \\
85 \\
103 \\
94 \\
85\end{array}$ & $\begin{array}{r}88 \\
86 \\
107 \\
134 \\
121 \\
100 \\
116 \\
137 \\
126\end{array}$ & $\begin{array}{r}68 \\
86 \\
97 \\
100 \\
103 \\
99 \\
86 \\
97 \\
92\end{array}$ & $\begin{array}{r}128 \\
99 \\
110 \\
133 \\
117 \\
101 \\
136 \\
142 \\
134\end{array}$ \\
\hline Mean & & & & $82^{2}$ & $80^{1}$ & $86^{1}$ & $91^{1}$ & 113 & $92^{2}$ & $122^{1}$ \\
\hline
\end{tabular}

${ }^{1} \mathrm{P}<0.01 ;{ }^{2} \mathrm{P}<0.05$; difference from predicted normal values.

The co uptake was also assessed in terms of the transfer coefficient (KCO), which was obtained by dividing TLCO by the alveolar volume (VA) estimated by helium dilution during the breath-holding manoeuvre.

Maximum expiratory flow-volume (MEFV) curves were obtained using a pressure-corrected variable volume plethysmograph (Mead, 1960), in which the seated subject performed a forced expiration from TLC through a Fleisch pneumotachograph, the flow at the mouth being displayed against change in thoracic gas volume (TGV) on a storage oscilloscope, from which MEFV curves were copied. The maximum value of peak expiratory flow rate (PEFR) was taken from these curves. The nitrogen concentration during slow expiration, after a vital capacity inhalation of oxygen, was recorded in the same plethysmograph and displayed against volume. Closing volume $(\mathrm{CV})$ and the slope of the phase 3 plateau of $\mathrm{N}_{2}$ concentration $\left(\mathrm{N}_{2}\right.$ slope) were measured as the mean of between two and four records in which the expired volume was at least $95 \%$ VC. Closing capacity (CC) was derived by adding RV to CV.
Transpulmonary pressure was measured by the oesophageal balloon method (Milic-Emili et al, 1964) in four subjects seated in a variable volume plethysmograph. Several static expiratory pressurevolume curves were obtained in each subject, and the line of best fit was drawn by eye through at least three sets of data, where the pressure at a given volume agreed to $\pm 1 \mathrm{~cm} \mathrm{H}_{2} \mathrm{O}(0 \cdot 1 \mathrm{kPa})$.

The results were compared with predicted normal values obtained from the regression equations of Leiner et al (1963) for PEFR; Kory et al (1961) for $\mathrm{FEV}_{1}$ and FEV/VC in men; Ferris et al (1965) for $\mathrm{FEV}_{1}$ and Berglund et al (1963) for $\mathrm{FEV}_{1} / \mathrm{VC}$ in women; Goldman and Becklake (1959) for TLC, RV, and VC; Bradley et al (personal communication) for the results of the carbon monoxide uptake test, which were corrected for haemoglobin concentration by the equation of Cotes et al (1972) and Buist and Ross (1973a and b) for CV/VC, CC/TLC, and $\mathrm{N}_{2}$ slope. Statistical analysis of these comparisons was performed using the Wilcoxon matched-pairs signedranks test (Siegel, 1956). The MEFV curves were compared with the normal range from Gibson 
et al (1976), and the pressure-volume curves with a normal range derived from 20 non-smoking subjects aged $20-35$ years.

\section{Results}

$\mathrm{FEV}_{1}$, both in absolute terms and when expressed as a proportion of VC, was reduced compared with predicted normal values (table 2). Both TLC and VC were also reduced. RV tended to be raised, but this was only significant when expressed as a proportion of TLC.

$V_{A}$ measured by helium dilution during the 10 second breath-hold of the carbon monoxide uptake test was close to TLC measured plethysmographically, having a mean value of $98 \%$ TLC (table 3). Carbon monoxide transfer factor (TLCO) was reduced in nearly all subjects, to a mean for the whole group of $77 \%$ of predicted normal values. Kco was similarly reduced to $80 \%$ of predicted normal values.

Analysis of the MEFV curves showed that PEFR was reduced in all except one subject (table 2), and that maximum flow was low throughout expiration, being particularly reduced at low lung volumes (fig 1). CV/VC was not significantly raised; and, indeed, when $\mathrm{CV}$ was related to predicted $\mathrm{VC}$, to eliminate the effects of the generally small VC in the group, the mean value was close to predicted (table 4). CC was, however, considerably raised, both as a proportion of actual TLC and when related to predicted
Table 3 Results of single breath carbon monoxide uptake test

\begin{tabular}{llcccc}
\hline $\begin{array}{l}\text { Case } \\
\text { No }\end{array}$ & $\begin{array}{l}\text { Haemoglobin } \\
\text { g/dl }\end{array}$ & $\begin{array}{l}V_{A} \\
\text { litre }\end{array}$ & $\begin{array}{l}V_{A} / T L C \\
\text { per cent }\end{array}$ & $\begin{array}{l}\text { TLCo } \\
\text { Per cent of predicted } \\
\text { normal values }\end{array}$ \\
\hline 1 & $20 \cdot 4$ & $4 \cdot 3$ & 102 & 90 & 122 \\
2 & $20 \cdot 7$ & $5 \cdot 3$ & 91 & 60 & 74 \\
3 & $25 \cdot 6$ & $7 \cdot 0$ & 96 & 85 & 82 \\
$3^{*}$ & $16 \cdot 6$ & $7 \cdot 0$ & 96 & 72 & 70 \\
4 & $19 \cdot 4$ & $6 \cdot 4$ & 102 & 86 & 79 \\
5 & $23 \cdot 6$ & $5 \cdot 8$ & 102 & 87 & 80 \\
6 & $20 \cdot 5$ & $5 \cdot 3$ & 100 & 102 & 93 \\
7 & $19 \cdot 7$ & $4 \cdot 0$ & 103 & 57 & 65 \\
8 & $15 \cdot 3$ & $5 \cdot 0$ & 98 & 53 & 51 \\
9 & $17 \cdot 2$ & $3 \cdot 8$ & 90 & 79 & 86 \\
Mean & & & 98 & $77^{1}$ & $80^{2}$ \\
& & & & & \multicolumn{3}{c}{} \\
\hline
\end{tabular}

Results for TLCO and KCO after correction for haemoglobin concentration are shown.

${ }^{1} P<0.01 ;{ }^{2} P<0.05$; difference from predicted normal values.

*This patient was studied before and after chronic venesection.

TLC. $\mathrm{N}_{2}$ slope was not significantly different from predicted normal values.

\section{Discussion}

Ventilatory function and gas transfer in this welldefined group of patients with the Eisenmenger syndrome shows a consistent, albeit mild, defect. The reduction in TLC, VC, and TLCo are similar to but more severe than those found by HallidieSmith et al (1977) in patients with persistent pulmonary hypertension after repair of large ventricular septal defects. In that series, however, a part of

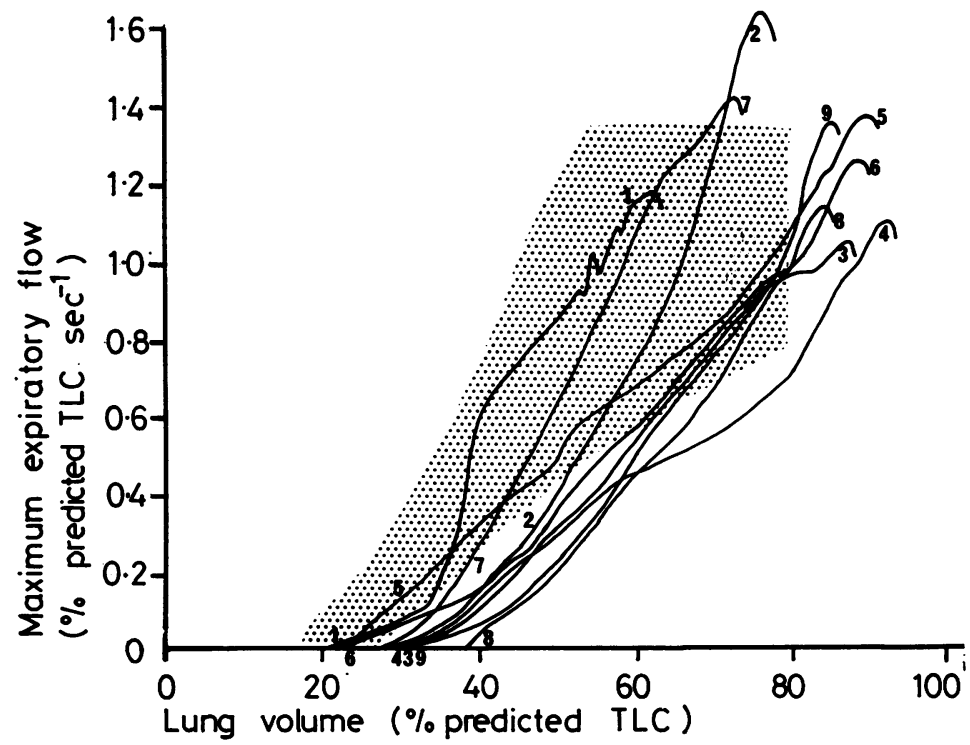

Fig 1 MEFV curves for the nine patients with a range (stippled area) for 16 normal non-smoking subjects. 
Table 4 Results of single breath nitrogen test

\begin{tabular}{|c|c|c|c|c|c|c|c|}
\hline Case No & $\begin{array}{l}C V \\
\text { litre }\end{array}$ & $\begin{array}{l}N_{2} \text { slope } \\
\text { Per cent/litre }\end{array}$ & $\begin{array}{l}\text { CVIVC } \\
\text { Per cent of } \\
\text { predicted } \\
\text { normal values }\end{array}$ & CV/Predicted $/ V C$ & $C C / T L C$ & CC/Predicted TLC & $N_{2}$ slope \\
\hline $\begin{array}{l}1 \\
2 \\
3 \\
4 \\
5 \\
6 \\
7 \\
8 \\
9\end{array}$ & $\begin{array}{l}0.46 \\
0.60 \\
0.75 \\
0.28 \\
0.40 \\
0.37 \\
0.34 \\
0.50 \\
0.27\end{array}$ & $\begin{array}{l}1.81 \\
1.40 \\
0.70 \\
0.53 \\
0.74 \\
1.05 \\
1.98 \\
2.33 \\
0.53\end{array}$ & $\begin{array}{r}192 \\
91 \\
129 \\
73 \\
110 \\
102 \\
129 \\
129 \\
107\end{array}$ & $\begin{array}{r}127 \\
78 \\
125 \\
66 \\
113 \\
99 \\
98 \\
111 \\
95\end{array}$ & $\begin{array}{l}163 \\
110 \\
135 \\
136 \\
129 \\
138 \\
163 \\
171 \\
171\end{array}$ & $\begin{array}{r}112 \\
95 \\
131 \\
137 \\
133 \\
137 \\
139 \\
165 \\
160\end{array}$ & $\begin{array}{r}199 \\
120 \\
70 \\
56 \\
80 \\
84 \\
156 \\
175 \\
43\end{array}$ \\
\hline Mean & & & 118 & 101 & $146^{1}$ & $134^{1}$ & 109 \\
\hline
\end{tabular}

${ }^{1} \mathrm{P}<0.01$; difference from predicted normal values.

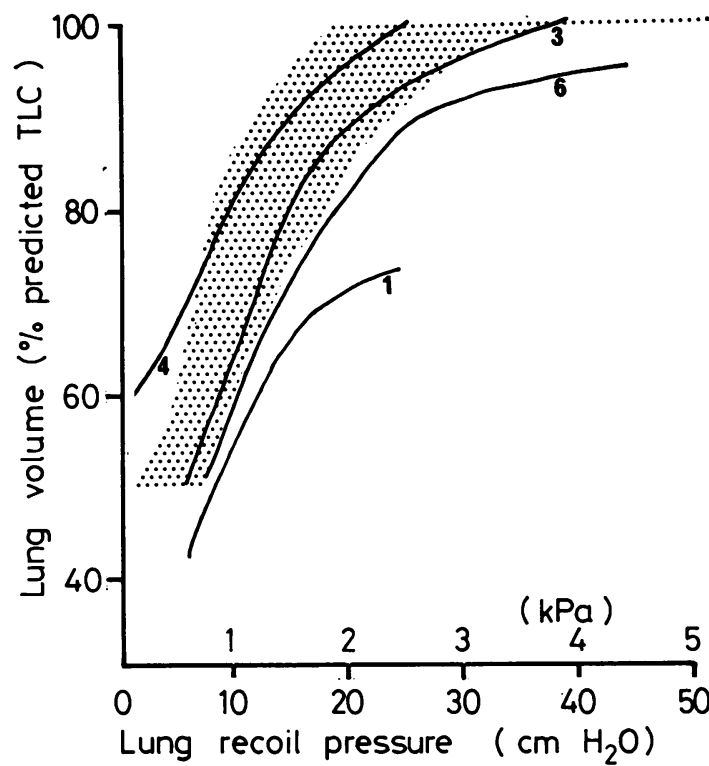

Fig 2 Pressure-volume curves for four of the patients with a range (stippled area) for 20 normal non-smoking subjects.

the ventilatory defect could have been secondary to cardiac surgery, which had not been performed on any of the patients in this series. One explanation for the decreased TLC and VC might be cardiac enlargement. Comparison of the reduction in TLC from the predicted normal value with cardiac volume assessed from biplane chest radiographs by the ellipsoid method (Barnhard et al, 1960) showed no correlation. Probably, therefore, the reduced TLC is not solely caused by cardiac enlargement, but may result from defective pulmonary growth, possibly secondary to reduced growth of the thoracic cavity. The low values of
FEV and PEFR are probably partly due to the reduced lung volumes.

The low $\mathrm{FEV}_{1} / \mathrm{VC}$, disproportionately reduced maximum expiratory flow at low lung volumes, and raised $\mathrm{RV}$ and $\mathrm{CC}$ all indicate mild airflow obstruction. The two subjects who smoked had the greatest reduction in PEFR and were also both below average for the group in $\mathrm{FEV}_{1} / \mathrm{VC}$. The reduction in maximum flow at low lung volumes in these two subjects, however, was average for the group; and seems, therefore, to be caused by pulmonary vascular disease rather than by smoking. Airflow obstruction in pulmonary vascular disease may be due either to loss of elastic recoil at low lung volumes or to intrinsic narrowing or obliteration of small airways. The pressurevolume curve of patient 4 suggested that the former mechanism might be important. A similar appearance of the pressure-volume curve has been described in patients with mitral stenosis (Wood et al, 1971).

Although the development of the Eisenmenger syndrome due to simple intracardiac defects is now rare, it still occurs early in the history of some infants with more complicated cardiac anatomy, such as transposition of the great arteries. Byrne et al (1978) have emphasised the need to diagnose pulmonary vascular disease early in these infants, who are otherwise only suitable for palliative surgery. The nitrogen-13 test was encouraging in this respect (McKenzie et al, 1977), but its mechanism remains uncertain. Although this study has shown a ventilatory defect including considerably raised closing capacity in the Eisenmenger syndrome, reduced ventilation of perfused alveoil is unlikely to be the mechanism of delayed clearance of injected nitrogen-13. There are two lines of evidence for this. Firstly, the close correlation of OVA and TLC indicates that the proportion of TLC in the patients in this series that has not equilibrated with 
helium during a 10 second breath-hold is small. Secondly, the near-normality of the $\mathrm{N}_{2}$ slope shows that there is no significantly abnormal nonuniformity of alveolar ventilation in the Eisenmenger subjects.

The considerable inter-individual variation in $\mathrm{CV}$ and $\mathrm{N}_{2}$ slope in this study was probably partly due to the intrinsic variability and poor repeatability of the single breath nitrogen test (McCarthy et al, 1975). For this reason, as well as difficulty in performing the test in infants, the abnormally raised closing capacity is unlikely to be useful for detecting pulmonary vascular disease.

The other major abnormality shown in this study was the reduction in TLco which after correction for haemoglobin concentration was more than $10 \%$ below predicted normal values in seven of the nine patients and averaged $77 \%$ predicted. Previous studies have shown that TLCo tends to be lower in patients with intracardiac defects who have developed pulmonary vascular disease (Auchincloss et al, 1959; McCredie et al, 1964). The reduction was greater in this study than in previous studies, perhaps reflecting the severity of pulmonary vascular disease in the patients studied. TLCo is also reduced in primary pulmonary hypertension (Burgess, 1974).

The correction for haemoglobin concentration (Cotes et al, 1972) in this study reduced the measured TLCo by a mean of $10 \%$. The validity of this correction must be questioned since it assumes that the ratio of the alveolar membrane diffusing capacity (Dm) to the capillary blood volume $(\mathrm{Vc})$ is 0.7 . It is likely that hypertensive pulmonary vascular disease predominantly reduces Vc (Burgess, 1974), and that the ratio $\mathrm{Dm} / \mathrm{Vc}$ is, therefore, greater than 0.7 . This is supported by our finding that the corrected transfer factor tended to be lower in those patients with the lowest haemoglobin; and that the corrected TLco in patient 3 fell after venesection. Furthermore, although the correction has been shown to be accurate in anaemia (Cotes et al, 1972; Clark et al, 1978), two studies (Burgess and Bishop, 1963; Herbert et al, 1965) have shown that it is too small in polycythaemia. Thus the quoted results in this study for TLCO and Kco may be slight overestimates; and the true abnormality of gas transfer may have been greater than our results indicate.

In infants without polycythaemia, or in whom the degree of polycythaemia is fairly constant, repeated measurements of carbon monoxide transfer factor, as first suggested by Auchincloss et al (1959), might allow early diagnosis of pulmonary vascular disease. Naturally, the single-breath technique would not be suitable for this, but a steady state technique would be feasible. When pulmonary blood flow is high in the absence of pulmonary vascular disease the TLCo will probably be raised (Auchincloss et al, 1959; McCredie et al, 1964); although Bedell (1961) found this only to be the case with atrial septal defects. With the development of pulmonary vascular disease, the TLCo should progressively diminish. It would also be expected to decrease should the intracardiac defects spontaneously close, but this is unlikely to produce clinical confusion.

\section{References}

Auchincloss, J H, Gilbert, R, and Eich, R H (1959). The pulmonary diffusing capacity in congenital and rheumatic heart disease. Circulation, 19, 232-241.

Barnhard, H J, Pierce, J A, Joyce, J W, and Bates, J H (1960). Roentgenographic determination of total lung capacity: a new method evaluated in health, emphysema and congestive heart failure. American Journal of Medicine, 28, 51-60.

Bedell, G N (1961). Comparison of pulmonary diffusing capacity in normal subjects and in patients with intracardiac septal defects. Journal of Laboratory and Clinical Medicine, 57, 269-280.

Berglund, E, Birath, G, Bjure, J, Grimby, G, Kjellmer, I, Sandqvist, L, and Söderholm, B (1963). Spirometric studies in normal subjects. Acta Medica Scandinavica, 173, 185-198.

Buist, A S, and Ross, B B (1973a). Predicted values for closing volumes using a modified single breath nitrogen test. American Review of Respiratory Diseases, 107, 744-752.

Buist, A S, and Ross, B B (1973b). Quantitative analysis of the alveolar plateau in the diagnosis of early airway obstruction. American Review of Respiratory Diseases, 108, 1078-1087.

Burgess, J H, and Bishop, J M (1963). Pulmonary diffusing capacity and its subdivisions in polycythemia vera. Journal of Clinical Investigation, 42, 997-1008.

Burgess, J H (1974). Pulmonary diffusing capacity in disorders of the pulmonary circulation. Circulation, 49, 541-550.

Byrne, J, Clarke, D, Taylor, J F N, Macartney, F, N de Leval, M, and Stark, J (1978). Treatment of N patients with transposition of great arteries and $\mathrm{N}$ pulmonary vascular obstructive disease. British Heart Journal, 40, 221-225.

Clark, E H, Woods, R L, and Hughes, J M B (1978). Effect of blood transfusion on the carbon monoxide transfer factor of the lung in man. Clinical Science and Molecular Medicine, 54, 627-631.

Cotes, J E, Dabbs, J M, Elwood, P C, Hall, A M, McDonald, A, and Saunders, M J (1972). Irondeficiency anaemia; its effect on transfer factor for the lung (diffusing capacity) and ventilation and cardiac frequency during sub-maximal exercise. Clinical Science, 42, 325-335. 
Dubois, A B, Botelho, S Y, Bedell, G N, Marshall, R, and Comroe, J H jun (1956). A rapid plethysmographic method for measuring thoracic gas volume: a comparison with a nitrogen washout method for measuring functional residual capacity in normal subjects. Journal of Clinical Investigation, 35, 322326.

Ferris, B G jun, Anderson, D O, and Zickmantel, R (1965). Prediction values for screening tests of pulmonary function. American Review of Respiratory Diseases, 91, 252-261.

Gibson, G J, Pride, N B, O'Cain, C, and Quagliato, $R$ (1976). Sex and age differences in pulmonary mechanics in normal non-smoking subjects. Journal of Applied Physiology, 41, 20-25.

Goldman, H I, and Becklake, M R (1959). Respiratory function tests: normal values at median altitudes and the prediction of normal results. American $R e$ view of Tuberculosis, 79, 457-467.

Hallidie-Smith, $K$ A, Wilson, $R$ S E, Hart, A, and Zeidifard, E (1977). Functional status of patients with large ventricular septal defect and pulmonary vascular disease six to 16 years after surgical closure of their defect in childhood. British Heart Journal, 39, 1093-1101.

Herbert, S J, Weill, H, Stuckey, W J, Urner, C, Gonzales, E, and Ziskind, M M (1965). Pulmonary diffusing capacity in polycythemic states before and after phlebotomy. Diseases of the Chest, 48, 408415.

Kory, R C, Callahan, R, Boren, H G, and Syner, J C (1961). The veterans administration-army cooperative study of pulmonary function: 1. Clinical spirometry in normal men. American Journal of Medicine, 30, 243-258.

Kimball, K G, and McIlroy, M B (1966). Pulmonary hypertension in patients with congenital heart disease, pre- and post-operative hemodynamics, pulmonary function and criteria for surgical closure of defects. American Journal of Medicine, 41, 883897.

Leiner, G C, Abramowitz, S, Small, M J, Stenby, V B, and Lewis, W A (1963). Expiratory peak flow rate. American Review of Respiratory Diseases, 88, 644 651.

McCarthy, D S, Craig, D B, and Cherniack, $\mathbf{R}$ M (1975). Intraindividual variability in maximal ex- piratory flow-volume and closing volume in asymptomatic subjects. American Review of Respiratory Diseases, 112, 407-411.

McCredie, R M, Lovejoy, F W, and Yu, P N (1964). Pulmonary diffusing capacity and pulmonary capillary blood volume in patients with intracardiac shunts. Journal of Laboratory and Clinical Medicine, 63, 914-923.

McDermott, M, McDermott, T J, and Collins, M M (1968). A portable bellows spirometer and timing unit for the measurement of respiratory function. Medical Biology and Engineering, 6, 291-302.

McIlroy, M B, and Apthorp, G H (1958). Pulmonary function in pulmonary hypertension. British Heart Journal, 20, 397-402.

McKenzie, S A, MacArthur, C G C, Godfrey, S, and Hallidie-Smith, K A (1977). Hypertensive pulmonary vascular disease in children: detection by radioactive nitrogen $\left({ }^{13} \mathrm{~N}\right)$ inhalation and injection. British Heart Journal, 39, 866-871.

Mead, J (1960). Volume displacement body plethysmograph for respiratory measurements in human subjects. Journal of Applied Physiology, 15, 736-740.

Milic-Emili, J, Mead, J, Turner, J M, and Glauser, E M (1964). Improved technique for estimating pleural pressure from esophageal balloons. Journal of Applied Physiology, 19, 207-211.

Ogilvie, C M, Forster, R E, Blakemore, W S, and Morton, J W (1957). A standardised breath-holding technique for the clinical measurement of the diffusing capacity of the lung for carbon monoxide. Journal of Clinical Investigation, 36, 1-17.

Siegel, S (1956). Nonparametric Statistics for the Behavioral Sciences. McGraw-Hill, New York.

Wood, T E, McLeod, P, Anthonisen, N R, and Macklem, P T (1971). Mechanics of breathing in mitral stenosis. American Review of Respiratory Diseases, 104, 52-60.

Woolf, C R (1963). Pulmonary function in adults with intracardiac septal defect. Circulation, 27, 261-267.

Requests for reprints to: Dr C G C MacArthur, Department of Medicine (Clinical Cardiology), Hammersmith Hospital, Ducane Road, London W12 0HS. 